\title{
Finite element analysis on the optimal material choice and cavity design parameters for MOD inlays exposed to different force vectors and magnitudes
}

\author{
Sener-Yamaner, Isıl Damla ; Ekici, Bülent ; Sertgöz, Atilla ; Yuzbasioglu, Emir ; Özcan, Mutlu
}

\begin{abstract}
This simulation study evaluated the effect of three different inlay materials (composite, glass ceramic, zirconia), cavity design parameters (isthmus width and depth) and different force vectors and magnitudes on the stress distribution within mesio-occlusal-distal (MOD) inlays and the remaining enamel and dentin. The mechanical performance of inlays was evaluated using 3-D finite element analysis (FEA) method. Three different restoration materials and hard tissues of the restored tooth with different cavity depth $(2-5 \mathrm{~mm})$ and width (2-4 $\mathrm{mm}$ ) were exposed to occlusal loading with different magnitudes from 10 to $130 \mathrm{~kg}$ at varying angles between $0^{\circ}$ and $15^{\circ}$. The maximum von Mises stresses were calculated for the inlays, tooth structure and bonded surfaces. Response Surface Optimization method was implemented into the finite element software package in order to design cavity shapes with more favourable interfacial stresses for bonded restorations under occlusal loading. Teeth restored with resin composite exhibited the highest von Mises Stress, followed by glass ceramic and zirconia. The increase in isthmus width decreased interfacial shear stresses in zirconia MOD inlay but the increase in cavity depth did not change the stress levels for all three materials. According to mechanical safety factor, inlay and tooth structure remained within the mechanical limits in three parameters (material, magnitude of force, cavity shape) but negatively affected by the force vector.
\end{abstract}

DOI: https://doi.org/10.1080/01694243.2016.1195953

Posted at the Zurich Open Repository and Archive, University of Zurich

ZORA URL: https://doi.org/10.5167/uzh-146596

Journal Article

Accepted Version

Originally published at:

Sener-Yamaner, Isıl Damla; Ekici, Bülent; Sertgöz, Atilla; Yuzbasioglu, Emir; Özcan, Mutlu (2017). Finite element analysis on the optimal material choice and cavity design parameters for MOD inlays exposed to different force vectors and magnitudes. Journal of Adhesion Science and Technology, 31(1):8-20.

DOI: https://doi.org/10.1080/01694243.2016.1195953 
Finite Element Analysis on the Optimal Material Choice and Cavity Design

Parameters for MOD Inlays Exposed to Different Force Vectors and Magnitudes

Isıl Damla Sener-Yamaner, DDS, PhDa / Bülent Ekici, $\mathrm{PhD}^{\mathrm{b}}$ / Atilla Sertgöz, DDS, PhD $^{c} /$ Emir Yüzbaşıoğlu, DDS, PhD ${ }^{d, e} /$ Mutlu Özcan DDS, Dr.med.dent., PhDe,f

${ }^{a}$ Assistant Professor, Department of Prosthodontics, Faculty of Dentistry, Istanbul Aydın University, Istanbul, Turkey

${ }^{b}$ Professor, Department of Mechanical Engineering, Faculty of Engineering, Marmara University, İstanbul, Turkey

'Professor, Department of Prosthodontics, Faculty of Dentistry, Marmara University, Istanbul, Turkey

${ }^{d}$ Assistant Professor, Department of Prosthodontics, School of Dentistry, Istanbul Medipol University, Istanbul, Turkey

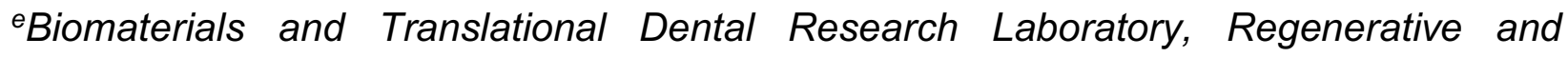
Restorative Medical Research Center (REMER), Istanbul Medipol University, Istanbul, Turkey

${ }^{f}$ Professor, Head of Dental Materials Unit, Center for Dental and Oral Medicine, Clinic for Fixed and Removable Prosthodontics and Dental Materials Science, Zurich, Switzerland

Short title: Finite Element Analysis on MOD inlay materials 
Correspondance to: Dr.Emir Yuzbasioglu ,DDS, PhD, Assistant Professor, Istanbul Medipol University, School of Dentistry, Department of Prosthodontics, Ataturk Bulvarı, No:27, 34083, Fatih-Istanbul, Turkey, Phone: +90 21245349 53, Fax: +90 2125317555.

Abstract: This simulation study evaluated the effect of three different inlay materials (composite, glass ceramic, zirconia), cavity design parameters (isthmus width and depth) and different force vectors and magnitudes on the stress distribution within mesio-occlusal-distal (MOD) inlays and the remaining enamel and dentin. The mechanical performance of inlays was evaluated using 3-D finite element analysis (FEA) method. Three different restoration materials and hard tissues of the restored tooth with different cavity depth (2 to $5 \mathrm{~mm}$ ) and width (2 to $4 \mathrm{~mm}$ ) were exposed to occlusal loading with different magnitudes from 10 to $130 \mathrm{~kg}$ at varying angles between $0^{\circ}$ and $15^{\circ}$. The maximum von Mises stresses were calculated for the inlays, tooth structure and bonded surfaces. Response Surface Optimization method was implemented into the finite element software package in order to design cavity shapes with more favourable interfacial stresses for bonded restorations under occlusal loading. Teeth restored with resin composite exhibited the highest von Mises Stress, followed by glass ceramic and zirconia. The increase in isthmus width decreased interfacial shear stresses in zirconia MOD inlay but the increase in cavity depth did not change the stress levels for all three materials. According to mechanical safety factor, inlay and tooth structure remained within the mechanical limits in three parameters (material, magnitude of force, cavity shape) but negatively affected by the force vector.

Keywords: Cavity depth, cavity width, finite element analysis, MOD inlays 


\section{Introduction}

Large defects in molar teeth due to caries, fracture or endodontic treatments are frequently restored by the inlay restorations. The properties of restorative materials chosen for inlays should be similar to those of the original tooth structure in order to perform similar to natural tooth under chewing forces. Various dental materials such as amalgam, alloys, resin composite resin or ceramics have been used as inlay restorations but the trend is to use more tooth-coloured restorations even in the posterior regions of the mouth [1]. From biological perspective, tooth is composed of enamel (96\% inorganic, the rest water and organic), dentin (65-70\% minerals, the rest organic), cementum (45\% inorganic, $22 \%$ water and $33 \%$ organic) and dental pulp. While enamel is stiff and wear resistant at the outermost layer of the tooth crown, dentin is the underlying tissue occupying the major part of tooth both in weight and volume. On the other hand, pulp is the innermost vital soft tissue containing nerves, blood vessels, and other organic constituents and cementum is a layer of connective tissue that binds the roots of the teeth firmly to the gums and jawbone having lower hardness than dentin [2]. Teeth are very resilient structures that are designed to withstand the mastication loads of $700 \mathrm{~N}$ and above [3]. In fact, the average chewing force varies between 11 and $150 \mathrm{~N}$, where force peaks are $200 \mathrm{~N}$ in the anterior, $350 \mathrm{~N}$ in the posterior and $1000 \mathrm{~N}$ in bruxing patients [4]. Although teeth can withstand the conditions in most oral activities, tooth failure is still a significant concern in the field of restorative dentistry due to acidic beverages, cold or hot liquids and masticatory mechanical loads $[2,3]$.

Today, new generation resin composite, ceramic and monolithic zirconia materials are commonly used as a restoration material as they can reproduce the colour and translucency of natural teeth [5]. Among such materials, ceramics are substantially stiffer, 
harder and more wear resistant than resin composites [6], characterized by low flexural strength and fracture toughness [7]. Ceramic inlays are mainly composed of glass with some crystals added to increase their strength and can be manufactured in a laboratory using a press technique or milled chairside from prefabricated ceramic blocks with the help of computer aided design/computer-aided manufacturing (CAD/CAM) technology [8]. Despite the major advances such as improved wear resistance, strength, aesthetics and reduced water absorption, still polymerization shrinkage and microleakage remain unsolved problems [9]. Recently, resin composite blocks became available for use in CAD/CAM restorations, opening up a wider range of indications. Additional advantages of using resin composite blocks in CAD/CAM are milling time, conservation of tooth structure and milling such materials in thin layers $[9,10]$. One other material used in conjunction with CAD/CAM systems is zirconia, a crystalline dioxide of zirconia [5,11]. Zirconia is the strongest of dental ceramic with a flexural strength of $800-1200 \mathrm{MPa}$, fracture toughness of 6-8 MPa and compression resistance of about $2000 \mathrm{MPa}$, making the material suitable for high stress-bearing posterior restorations [12,13].

Several factors affect the fracture resistance of the inlays, namely type of material, fabrication technique, amount of tissue lost, type and magnitude of the occlusal load $[14,15]$. Some of these parameters and their combinations could be investigated using Finite Element Analysis (FEA) [6,7,16-23]. FEA has also been used for inlay materials in order to calculate stress distribution and determine failure risk [24-26]. Using FEA method, higher stresses in the internal surfaces of the ceramic inlays were noted than resin composite and the latter was recommended as it limits the stress intensity transmitted to the remaining tooth structures [24]. Similarly, when stress distribution was compared within the gold, ceramic and resin composite inlays and onlays, FEA method indicated higher stress concentrations in restorations with high elastic modulus where resin composite was 
suggested as the best choice of material for inlays and onlays [25]. Moreover, FE models showed lower contact tensile and shear stresses at the cement-tooth interface around the ceramic inlay compared to resin composite inlay models [26]. On the contrary, one other FE study reported that ceramic inlay models reduce tension at the dentin-adhesive interface and prevent debonding at the dentin restoration interface compared to the resin composite inlay models [27].

In fact, fracture resistance of any inlay material is dictated by the remaining tooth substance and the geometric design of the cavity. Fracture resistance of tooth decreases with the increased width and depth of cavity preparation [20]. The average width of inlays is two thirds of the intercuspal distance of teeth [7] where wider inlay cavities receives less stress when their cusps are protected [28]. Another FE study also showed that an inlay cavity with a narrow isthmus had high stresses in the ceramic onlay compared to those with wider isthmus [29]. The most crucial factor in the weakening of cusps is the cavity depth and the width of the isthmus alone seemed to be less of importance [30]. Currently, the controversial results are paradoxical for the clinicians to make recommendations during the selection of the material and determination of the cavity design of the inlay restorations.

The objectives of this simulation study therefore, were to a) investigate the effect of three different inlay materials (composite, glass ceramic, zirconia), cavity design parameters (isthmus width and depth) and different force vectors and magnitudes on the stress distribution within mesio-occlusal-distal (MOD) inlays and the remaining enamel and dentin and b) determine the optimal material and cavity design combination for the MOD inlays within mechanical safety limits of the materials. The hypotheses tested were that a) inlay material having higher elasticity would show better mechanical safety for bonded surfaces between the inlay and tooth structure, b) increased cavity width and depth would decrease 
the stress distribution at interfaces and c) increased force magnitude and angulation would decrease the safety factor the inlay and tooth structure.

\section{Materials and Methods}

Finite element analysis (FEA)

A finite element (FE) model of a mandibular first molar with inlay restoration, containing 45678 tetrahedron elements, was created from CT images of a real tooth using a FEA (ANSYS,

Inc.

Canonsburg, PA, USA) (Figs. 1a-d). Ideal adhesion was assumed between the tooth and the restoration. Occlusal load was simulated to apply pressure onto the tooth (Figs. 2a-d). Force was applied to the model as an occlusal load in different magnitudes between 10 to $130 \mathrm{~kg}$ and at varying angles ranging from $0^{\circ}$ to $15^{\circ}$ (Figs. 2a-d). The assumption of linear elastic isotropic material behaviour as a potential simplification for the complexity of FEA simulations was pursued, assuming material properties of enamel, dentin and filling materials as isotropic and linearly elastic (Table 1). Since the pulp is much softer than the other tissues or materials, it was excluded from the FEA model in order to simplify the analysis [25]. Maximum shear stress distribution calculated within enamel, dentin, inlay material and at the surfaces between the inlay and the cavity walls.

Initially, FEA identified the most highly stressed regions within the restored tooth, inlay and along the tooth-restoration interface. Based on these regions, response surface optimization was established.

Response surface optimization

For the present work, response surface optimization (RSO) was implemented into the finite element package (ANSYS) in order to design cavity shapes with more favourable interfacial stresses for inlay restorations under occlusal loading. Cavity depth (2 to $5 \mathrm{~mm}$ ) and width (2 to $4 \mathrm{~mm}$ ), force vector $\left(0^{\circ}\right.$ to $\left.1^{\circ}\right)$ and force magnitude (10 to $130 \mathrm{~kg}$ ) were 
considered as independent parameters for RSO calculations. A total of 25 different simulations were made according to the orthogonal array of four parameters, namely the depth and height of the cavity, force vector and magnitude.

\section{Results}

The highest maximum von Mises stress values were found at the interfaces for the resin composite and the lowest for zirconia inlay according to cavity width and depth and force magnitude parameters (Figs. 3a-c). Interfacial shear stresses remained constant with the increasing cavity depth, thus this parameter could be considered negligible in all three materials. Shear stresses did not change with respect to the width in ceramic and resin composite materials but it decreased in zirconia inlay and it decreased with decreasing pressure in all materials.

Safety factor describes the capacity of a system to bear forces beyond the expected or actual loads. In dentistry, factor of safety of 1.0 is commonly used for the dental structure or materials. Values below 1, can be considered biomechanically under risk. Safety factor calculated using RSO for the inlay, enamel and dentin in 25 different simulations indicated that force vector was the most effective factor on mechanical safety of the dentin, enamel and inlay (Table 2). In most simulation, safety factor of the inlay and tooth structure were below the mechanical limits when the force were angulated. The effect of cavity depth and width, and force magnitude showed that the increase in the cavity width did not affect the dentin and inlay safety factors but did increase safety factor of enamel (Fig. 4). Depth of the cavity did not have any effect on the safety factor of all materials. Safety factor of the dentin and enamel was positively affected with the increase in isthmus width. Increasing the depth of cavity affected the safety factor of both inlay and dentin positively but not the enamel. Decrease in force magnitude increased the safety factors of both enamel and 
dentin (Fig. 5). Safety factor of dentin, enamel and inlay were negatively affected with the increased force angulation but not by the force magnitude.

\section{Discussion}

This simulation study was undertaken in order to investigate the effect of three different inlay materials (composite, glass ceramic, zirconia), cavity design parameters (isthmus width and depth) and different force vectors and magnitudes on the stress distribution within MOD inlays and the remaining enamel and dentin and to suggest the optimum material. Based on the results of this study, since zirconia presented better performance under applied force showing reduced stress values in interfacial surfaces compared to other restorative materials, the first hypothesis could not be accepted. The increase in isthmus width decreased maximum interfacial shear stress values in zirconia MOD inlay but the increase in cavity depth did not increase the shear stress in MOD inlays made of all three materials. Thus, the second hypothesis could be partially accepted.

In dental research, FEA has been widely used to understand the mechanical behaviour of restored teeth [31]. FEA simulations could be considered efficient with lower costs and exhibits less risk, compared to experiments on real teeth or in patients. The method also enables the shape optimization process. The values from FEA are presented as stresses distributed in the structures under investigation where the results are expressed as maximum and minimum principal stresses, von Mises maximal stress [32,33]. This is associated with the fact that the normal criterion for the most engineering analyses deals with ductile materials such as steel and aluminium [34]. In fact, von Mises criterion is only valid for the ductile materials with equal compressive or tensile strength. However, materials exhibiting brittle behaviour such as ceramics, cements or resin composites presents reported values of compressive strength significantly greater than tensile strength [35]. Positive and negative values signify that the corresponding regions are subjected to 
tensile or compressive stresses [36]. Hence, it is not possible to implement the results from FEA directly to a clinical situation but it has to design the model in such a way that it mimics the real situation as closely as possible. FEA analysis must be interpreted with a certain amount of caution. Most of the studies to date modelled dental structures as isotropic and not orthotropic $[18,26,37]$. On the other hand, FEA model represents a static situation at the moment of load application and not an actual clinical situation. In reality, the loading of the structure is more dynamic and cyclic. The materials of the various tooth structures were assumed to be isotropic, homogenous and elastic, and that they remain such under applied loads. Therefore, in this study, a non-linear elastic-plastic material model was used instead of linear model [16].

In this simulation study, axial load between 10 to $130 \mathrm{~kg}$ was applied to the occlusal surface. The load represented approximately the average of the maximum bite forces in the premolar region [38]. It should be noted that a wide range of bite force have been reported in the literature (131-608 N), and the measured biting forces appear to be related to the measuring method, gender and age of the individual $[4,39,40]$. The choice of the applied load could affect the size and shape of the optimized cavity design [19].

The use of different materials for restoration substantially modifies the stress distribution in an originally healthy tooth. The difference between the elastic modulus of tooth and restorative material may be a source of stress in the dental structures. If the stress exceeds the yield strength of the materials, fracture of the restorative materials or the tooth may occur. The occlusal force leaning against the tooth axis causes the structure to bend, and the higher tensile stresses are produced. The oblique force loading on the dental structure is the major cause of dental damage and further attention should be paid to the importance of the occlusal adjustment. Many detrimental effects during restorative procedures are reported due to lack of understanding of biomechanical principles underlying treatment $[41,42]$. Nevertheless, the purpose of using products that have 
mechanical properties closer to dentin and enamel and obtaining best resistance and retention of the restoration would eliminate dislodgement of the restoration during occluding forces, simultaneously protecting the remaining tooth structure [41]. Typically, two mechanisms operate and cause failure, one being the lateral excursive movements resulting in lateral cuspal movements that generate tensile stresses along tooth restoration interface, and the other heavy forces in centric occlusion that cause vertical deformation on the tooth leading to compressive and shear stresses [16]. The presence of an occlusal restoration weakens the tooth structure and increases the stresses.

In this study, the increase in isthmus width decreased maximum stress values in zirconia inlay but the increase in cavity depth did not increase the shear stress in MOD inlays made of all three materials. These findings are contradictory to a previous report where the opposite was reported [43]. The differences in materials chosen and their mechanical properties selected during modelling might have affected the discrepancy.

Only bonded ceramics and resin composite address the favourable biomimetic principles of utmost tissue conservation and aesthetics. The choice of ceramics as an enamel replacement is advocated [44] and their stability relies primarily on the strength and thickness of the material [45] along with effective bonding to the underlying dental substrate [46], mimicking the function of the dentino-enamel junction [47]. Also, the development of ceramics that are stronger (such as lithium disilicate glass ceramic) but still etchable and machinable has extended the indications for bonded ceramic restorations [11]. The performance of resin composite resins through a superior bond between the different phases, enabling appropriate stress transfer were further improved after various post-polymerization procedures [48]. Generally, resin composite materials with their low elastic modulus are expected to better absorb functional stresses through deformation [49]. Interestingly however, in this study, zirconia, when used as a MOD inlay material, with its high elastic modulus presented better performance in that it transmitted less stress to 
enamel and dentin. This could be explained on the grounds that the material itself absorbed the applied magnitude of load before it was transmitted to the surrounding dental tissues. The adhesion of zirconia to the dental tissues is not ideal whereas in this study ideal conditions were simulated. This aspect should be further investigated focusing on the interface between the zirconia and enamel/dentin complex.

One study showed that increased depth and width of the cavity and lateral loading force increases the peak stress of tooth with inlays. Similarly, present study domonstrated negative effect of angulated force on the safety factor of both tooth and inlay [50].

Notably, FEA simulation conditions do not simulate the intraoral conditions completely. The restorations are subjected to cyclic loading in the mastication system and the physical properties of the actual materials tested may change over time in the aggressive oral environment. Thus, the results of computer simulations should be coupled with clinical findings and the results could be used for setting indications especially for worse-case conditions in clinical situations.

\section{Conclusions}

From this study, the following could be concluded:

1. The increase in isthmus width decreased maximum von Misses stresses in MOD inlays made of resin composite, ceramic and zirconia.

2. The increase in cavity depth did not increase the shear stress in MOD inlays made of all three materials.

3. Zirconia as an inlay material presented better performance under applied force owing to the reduced stress values in the tooth structure compared to other restorative materials. Materials with lower Young Moduli created more stress to the tooth structure. 


\section{Clinical Relevance}

MOD inlays made of zirconia may transmit less stress to the surrounding enamel and dentin under 10 to $130 \mathrm{~kg}$ occlusal loading simulation. Increase in cavity depth from 2 to 5 $\mathrm{mm}$ may not increase the shear stress but increase in isthmus width from 2 to $4 \mathrm{~mm}$ may be more detrimental for the MOD inlays made of CAD/CAM resin composite, ceramic and zirconia.

\section{Conflict of interest}

The authors did not have any commercial interest in any of the materials used in this study. 


\section{References}

1. Fron Chabouis H, Smail Faugeron V, Attal JP. Clinical efficacy of composite versus ceramic inlays and onlays: A systematic review. Dent Mater 2013;29:1209-1218.

2. Zhang YR, Du W, Zhou XD, Yu HY. Review of research on the mechanical properties of the human tooth. Int J Oral Sci 2014;6:61-69.

3. Yahyazadehfar M, Ivancik J, Majd H, An B, Zhang D, Arola D. On the mechanics of fatigue and fracture in teeth. Appl Mech Rev 2014;66:0308031-3080319.

4. Rezaei SMM, Heidarifar H, Arezodar FF, Azary A, Mokhtarykhoee S. Influence of connector width on the stress distribution of posterior bridges under loading. J Dent 2011;8:67-74.

5. Hamza TA, Ezzat HA, El-Hossary MM, Katamish HA, Shokry TE, Rosenstiel SF. Accuracy of ceramic restorations made with two CAD/CAM Systems. J Prosthet Dent 2013;109:83-87.

6. Hübsch PF, Middleton J, Knox J. A finite element analysis of the stress at the restoration tooth interface comparing inlays and bulk fillings. Biomaterials 2000;21:1015-1019.

7. Dejak B, Mlotkowski A, Romanowicz M. Strength estimation of different designs of ceramic inlays and onlays in molars based on the Tsai-Wu Failure Criterion. J Prosthet Dent 2007;98:89-100.

8. Holberg C, Rudzki-Janson I, Wichelhaus A, Winterhalder P. Ceramic inlays: Is the inlay thickness an important factor influencing the fracture risk? J Dent 2013;41: 628-635.

9. Zaruba M, Kasper R, Kazama R, Wegehaupt FJ, Ender A, Attin T, Mehl A. Marginal adaptation of ceramic and composite inlays in minimally invasive mod cavities. Clin Oral Investig 2014;18:579-587. 
10. Peutzfeldt A, Asmussen E. The effect of postcuring on quantity of remaining double bonds, mechanical properties, and in vitro wear of two resin composites. J Dent 2000;28:447-452.

11. Schlichting LH, Maia HP, Baratieri LN, Magne P. Novel-design ultra-thin CAD/CAM composite resin and ceramic occlusal veneers for the treatment of severe dental erosion. $\mathrm{J}$ Prosthet Dent 2011;105:217-226.

12. Al-Amleh B, Lyons K, Swain M. Clinical trials in zirconia: a systematic review. J Oral Rehabil 2010;37:641-652.

13. Ma L, Guess PC, Zhang Y. Load bearing properties of minimal-invasive monolithic lithium disilicate and zirconia occlusal onlays: finite element and theoretical analyses. Dent Mater 2013;29:742-751.

14. Bremer BD, Geurtsen W. Molar fracture resistance after adhesive restoration with ceramic inlays or resin-based composites. Am J Dent 2001;14:216-220.

15. Liu X, Fok A, Li H. Influence of restorative material and proximal cavity design on the fracture resistance of MOD inlay restoration. Dent Mater 2014;30;327-333.

16. Shi Li, Fok ASL, Qualtrough A. A two stage shape optimization process for cavity preparation. Dent Mater 2008; 24:1444-1453.

17. Yamanel K, Çağlar A, Gülşah K, Özden UA. Effects of different ceramic and composite materials on stress distribution in inlay and onlay cavities: 3-D finite element analysis. Dent Mater J 2009;28:661-670.

18. Campos RE, Soares CJ, Quagliatto PS, Soares PV, de Oliveira OB Jr, Santos-Filho PC, Salazar- Marocho SM. In vitro study of fracture load and farcture pattern of ceramic crowns: A Finite element and fractography analysis. J Prosthodont 2011;20:447-455.

19. Borcic J, Braut A. Finite Element Analysis in Dental Medicine, Finite Element Analysis New Trends and Developments, Dr. Farzad Ebrahimi (Ed.), ISBN: 978-953-51-0769-9, InTech, 2012, pp:3-20. 
20. Field C, Li Q, Li W,Thompson M,Swain M. A comparative mechanical and bone remodelling study of all ceramic posterior inlay and onlay fixed partial dentures. J Dent 2012;40:48-56.

21. Magne P, Stanley K, Schlichting LH. Modeling of ultrathin occlusal veneers. Dent Mater 2012;28:777-782.

22. Holdberg C, Winterhalder P, Wichelhaus A, Hickel R, Huth K. Fracture risk of lithium disicate ceramic inlays: A finite element analysis. Dent Mater 2013;29:1244-1250.

23. Chun $\mathrm{K}$, Choi $\mathrm{H}$, Lee J, Comparison of mechanical property and role between enamel and dentin in the human teeth. J Dent Biomech 2014;5:1758736014520809.

24. Ausiello P, Rengo S, Davidson CL, Watts DC. Stress distributions in adhesively cemented ceramic and resin-composite Class II inlay restorations: a 3D-FEA study. Dent Mater 2004;20:862-872.

25.Dejak B, Mlotkowski A. Three-dimensional finite element analysis of strength and adhesion of composite resin versus ceramic inlays in molars. $\mathrm{J}$ Prosthet Dent 2008;99:131-140.

26. Jiang $\mathrm{W}$, Bo $\mathrm{H}$, Yongchun $\mathrm{G}$, LongXing $\mathrm{N}$. Stress distribution in molars restored with inlays or onlays with or without endodontic treatment: A three dimensional finite element analysis. J Prosthet Dent 2010;103:6-12.

27.Magne P, Belser UC. Porcelain versus composite inlays/onlays: effects of mechanical loads on stress distribution, adhesion, and crown flexure. Int J Periodontics Restorative Dent 2003;23:543-555.

28.Farah JW, Dennison JB, Powers JM. Effects of design on stress distribution of intracoronal gold restorations. J Am Dent Assoc 1977;94:1151-1154.

29. Manhart J, Mehl A, Obermeier T, Hickel R. Finite element study on stress distribution in dependence on cavity width and materials properties. In: Academy of Dental Materials: Proceedings of Conference on Clinically Appropriate Alternatives to Amalgam: Biophysical 
Factors in Restorative Decision-Making, October 30-November 2, Munich, Germany, 269.1996;9:269.

30. Khera SC, Goel VK, Chen RC, Gurusami SA. Parameters of MOD cavity preparations: a 3-D FEM study, Part 2. Oper Dent 1991;16:42-54.

31. Romeed SA, Fok SL, Wilson NH. A Comparison of 2D and 3D finite element analysis of a restored tooth. J Oral Rehabil 2006;33:209-215.

32. Sorrentino R, Aversa R, Ferro V, Auriemma T, Zarone F, Ferrari M, Apicella A. Threedimensional finite element analysis of strain and stress distributions in endodontically treated maxillary central incisors restored with different post, core and crown materials. Dent Mater 2007;23:983-993.

33. Gonzalez-Lluch C, Rodriguez-Cervantes PJ, Sancho-Bru JL, Perez-Gonzales A, Barjau-Escribano A, Vergara-Monedero M, Forner-Navarro L. Influence of material and diameter of prefabricated posts on maxillary central incisors restored with crown. J Oral Rehabil 2009;36:737-747.

34. Perez-Gonzalez A, Iserte-Vilar JL, Gonzalez-Lluch C. Biomedical Engineering http://www.biomedical-engineering-online.com/content/10/1/44 (accessed 10 March 2012). 35. Craig R, Powers JM. Restorative Dental Materials. St Louis Mosby 2002;11

36. Lang L, Wang RF. Validation of finite element analysis in dental ceramics research. $J$ Prosthet Dent 2001;86:650-654.

37. Santos MBF, Silva Neto JP, Consani RLX, Mesquita MF. Three-dimensional finite element analysis of stress distribution in peri-implant bone with relined dentures and different heights of healing caps. J Oral Rehabil 2011;38:691-696.

38. Ferrario VF, Sforza C, Serrao G, Dellavia C, Tartaglia GM. Single tooth bite forces in healthy young adults. J Oral Rehabil 2004;31:18-22. 
39. Shinogaya T, Bakke M, Thomsen CE, Vilmann A, Matsumoto M. Bite force and occlusal load in healthy young subjects - a methodological study. Eur J Prosthodont Restor Dent 2000;8:11-15.

40. Shinogaya T, Bakke M, Thomsen CE, Vilmann A, Sodeyama A, Matsumoto M. Effects of ethnicity, gender and age on clenching force and load distribution. Clin Oral Invest 2001;5:63-68.

41. Ricardo J. Influence of the remaining coronal structure on the resistance of teeth with intraradicular retainer. Braz Dent J 2005;16:197-201.

42. Aggarwal S, Garg V. Finite element analysis of stress concentration in three popular brands of fiber posts systems used for maxillary central incisor teeth. $\mathrm{J}$ Conserv Dent 2011;14:293-296.

43. Lee MR, Cho $\mathrm{BH}$, Son $\mathrm{HH}$, Um CM, Lee IB. Influence of cavity dimension and restoration methods on the cusps deflection of premolars in composite restoration. Dent Mater 2007;23:288-295.

44. Magne P. Composite resins and bonded porcelain: The postamalgam era? J Calif Dent Assoc 2006;34:135-147.

45. Manhart J, Chen H, Hamm G, Hickel R. Buonocore Memorial Lecture. Review of the clinical survival of direct and indirect restorations in posterior teeth of the permanent dentition. Oper Dent 2004;29:481-508.

46. Bindl A, Mörmann WH. Survival rate of mono-ceramic and ceramic-core CAD/ CAMgenerated anterior crowns over 2-5 years. Eur J Oral Sci 2004;112:197-204.

47. Magne P, Belser U. Understanding the intact tooth and the biomimetic principle. In: Magne and Belser. Bonded Porcelain Restorations in the Anterior Dentition: A Biomimetic Approach. Chicago: Quintessence Publishing Co. 2002, pp.23-55.

48. Leinfelder KF. Indirect posterior composite resins. Compend Contin Educ Dent 2005;26:495-503. 
49. Magne P, Perakis N, Belser UC, Krejci I. Stress distribution of inlay-anchored adhesive fixed partial dentures: a finite element analysis of the influence of restorative materials and abutment preparation design. J Prosthet Dent 2002;87:516-527.

50. Zhang L, Lu Y, Yang BS, Guo Y, Li FP. The finite element analysis of stress distrubution in different size of MO cavities restored with composite resin inlays. Shanghai Kou Qiang Yi Xue 2015:24:170-176. 


\section{Captions to tables and figures:}

Tables:

Table 1. Mechanical properties of tooth and inlay restoration materials.

Table 2. Input parameters and finite element analysis results for orthogonal array.

\section{Figures:}

Figs. 1a-d Geometry of a) the whole model, b) dentin, c) enamel, d) inlay.

Figs. 2a-d Geometry of a) fixed surface, b) finite element model, c) rotation angle, d) point of force applied on the model.

Figs. 3a-c Effect of a) width, b) height and c) pressure on shear stress for ceramic, composite and zirconia, respectively. Note that shear stress does not change with respect to width of resin composite and ceramic but it decreases significantly with increasing width in zirconia. Shear stress decreases with decreasing pressure for all materials.

Fig. 4 Effect of a-c) width, d-f) height and g-i) pressure on enamel, dentin and inlay safety, respectively.

Fig. 5 Sensitivity analysis of input parameters. 
Tables:

\begin{tabular}{|l|c|c|}
\hline & Young Modulus (GPa) & Poisson's ratio \\
\hline Enamel & 84 & 0.33 \\
\hline Dentin & 18.6 & 0.31 \\
\hline Resin composite & 20 & 0.35 \\
\hline Glass ceramic & 90 & 0.3 \\
\hline Zirconia & 205 & 0.3 \\
\hline
\end{tabular}

Table 1. Mechanical properties of tooth and inlay restoration materials. 
Figures:

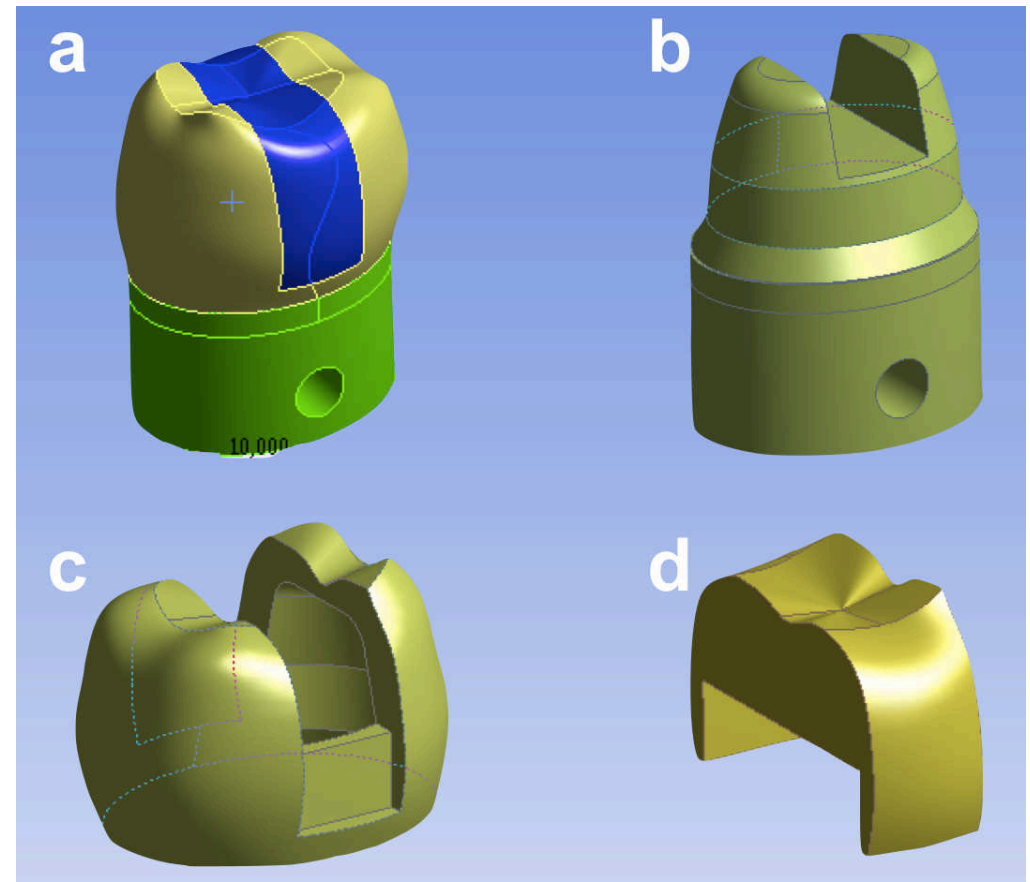

Figs. 1a-d Geometry of a)the whole model, b) dentin, c) enamel, d) inlay.

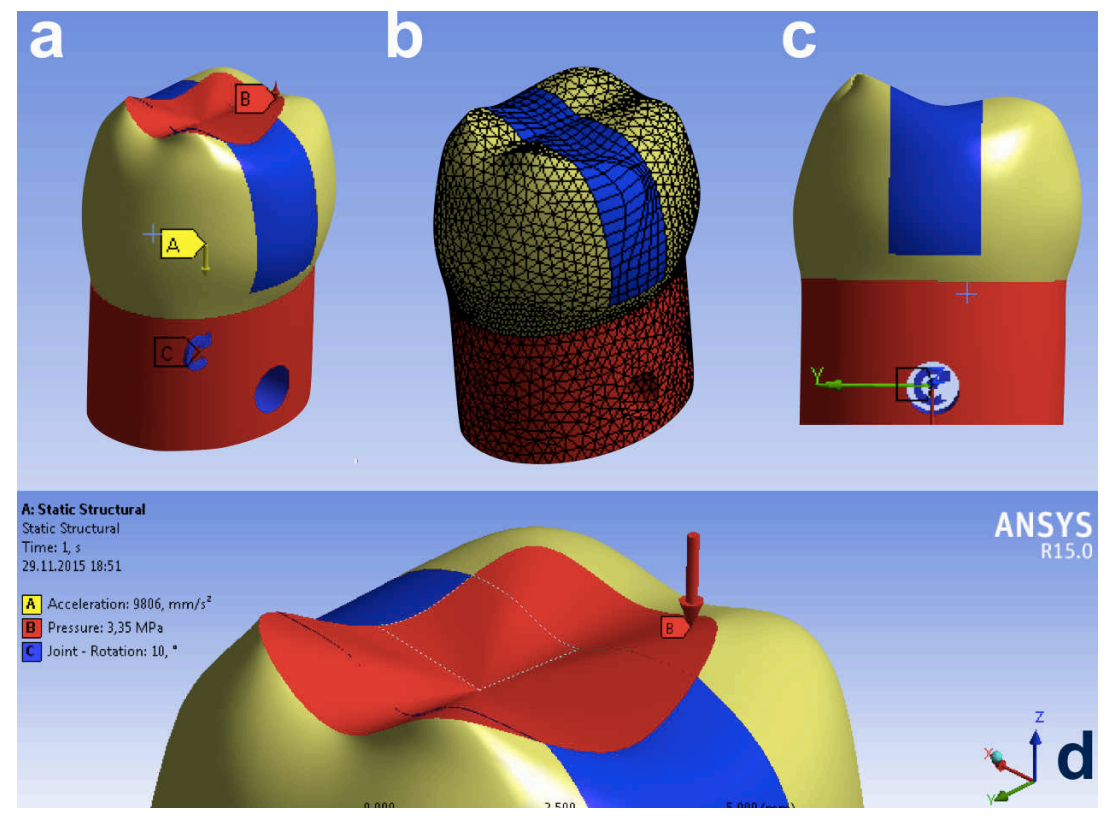

Figs. 2a-d Geometry of a) fixed surface, b) finite element model, c) rotation angle, d) point of force applied on the model. 

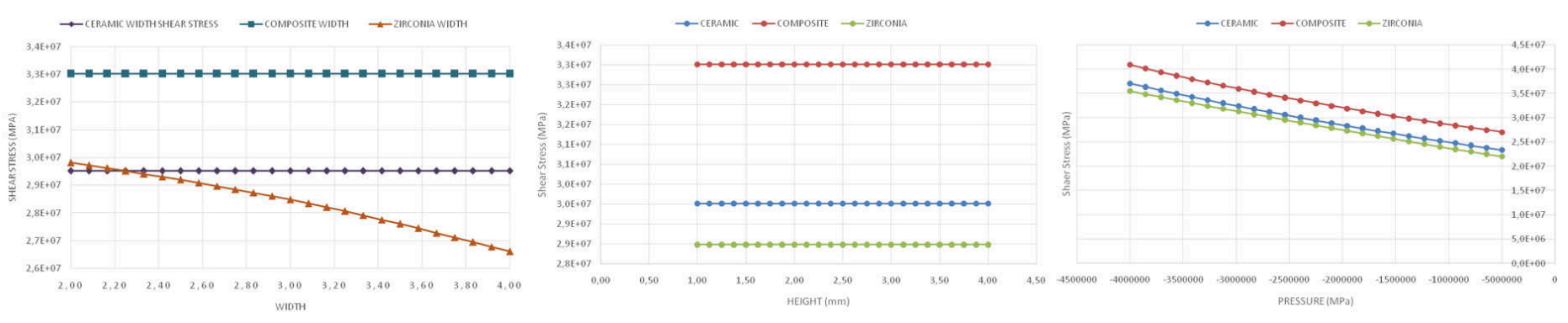

Figs. 3a-c Effect of a) width, b) height and c) pressure on shear stress for ceramic, composite and zirconia, respectively. Note that shear stress does not change with respect to width of resin composite and ceramic but it decreases significantly with increasing width in zirconia. Shear stress decreases with decreasing pressure for all materials.
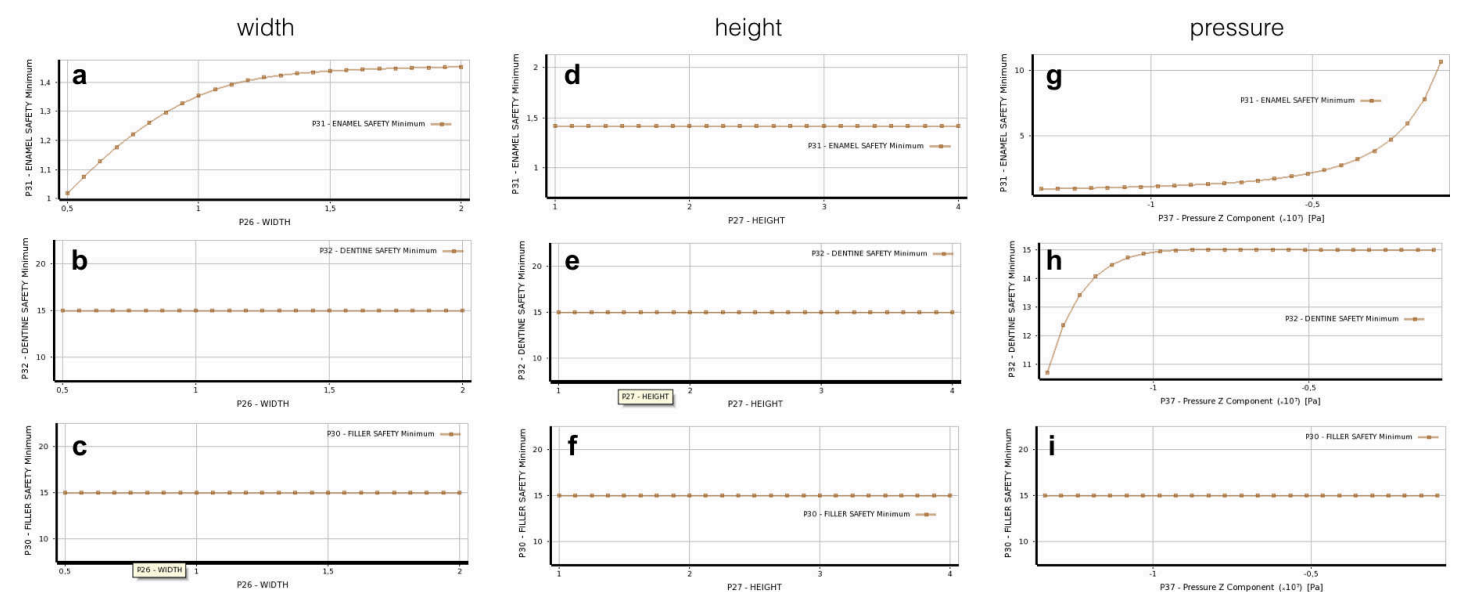

Fig. 4 Effect of a-c) width, d-f) height and $\mathbf{g - i}$ ) pressure on enamel, dentin and inlay safety, respectively.

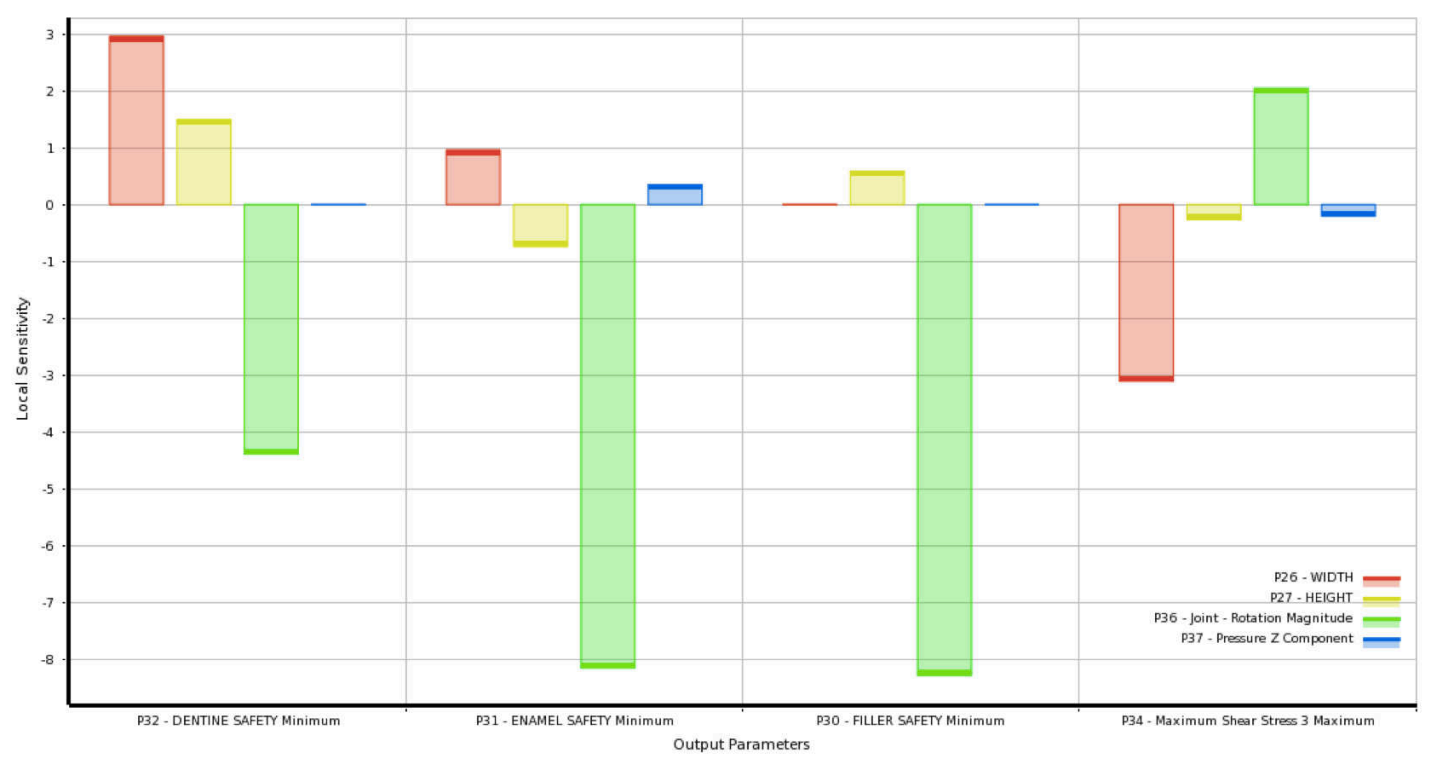

Fig. 5 Sensitivity analysis of input parameters. 


\begin{tabular}{|c|c|c|c|c|c|c|c|c|}
\hline Case & $\begin{array}{r}\text { Width } \\
(\mathrm{mm})\end{array}$ & $\begin{array}{c}\text { Height } \\
(\mathrm{mm})\end{array}$ & $\begin{array}{l}\text { Joint - Rotation } \\
\text { Angle (degree) }\end{array}$ & $\begin{array}{c}\text { Pressure } \mathrm{Z} \\
\text { Component }(\mathrm{Pa})\end{array}$ & $\begin{array}{l}\text { Dentine } \\
\text { Safety }\end{array}$ & $\begin{array}{l}\text { Enamel } \\
\text { Safety }\end{array}$ & $\begin{array}{l}\text { Filler } \\
\text { Safety }\end{array}$ & $\begin{array}{c}\text { Maximum Shear } \\
\text { Stress }(\mathrm{Pa})\end{array}$ \\
\hline 1 & 1,25 & 2,50 & 7,50 & $-7,20 E+06$ & 1,15 & 0,01 & 0,20 & $5,51 \mathrm{E}+08$ \\
\hline 2 & 0,50 & 2,50 & 7,50 & $-7,20 \mathrm{E}+06$ & 0,05 & 0,01 & 0,39 & $7,07 \mathrm{E}+08$ \\
\hline 3 & 2,00 & 2,50 & 7,50 & $-7,20 E+06$ & 0,56 & 0,01 & 0,16 & $5,75 E+08$ \\
\hline 4 & 1,25 & 1,00 & 7,50 & $-7,20 \mathrm{E}+06$ & 0,65 & 0,01 & 0,30 & $6,21 \mathrm{E}+08$ \\
\hline 5 & 1,25 & 4,00 & 7,50 & $-7,20 E+06$ & 0,37 & 0,01 & 0,34 & $3,22 E+08$ \\
\hline 6 & 1,25 & 2,50 & 0,00 & $-7,20 \mathrm{E}+06$ & 15,00 & 1,57 & 15,00 & $6,14 \mathrm{E}+06$ \\
\hline 7 & 1,25 & 2,50 & 15,00 & $-7,20 \mathrm{E}+06$ & 0,57 & 0,01 & 0,10 & $1,10 E+09$ \\
\hline 8 & 1,25 & 2,50 & 7,50 & $-1,34 \mathrm{E}+07$ & 1,17 & 0,01 & 0,21 & $5,50 \mathrm{E}+08$ \\
\hline 9 & 1,25 & 2,50 & 7,50 & $-1,00 E+06$ & 1,14 & 0,01 & 0,20 & $5,51 \mathrm{E}+08$ \\
\hline 10 & 0,72 & 1,44 & 2,22 & $-1,16 E+07$ & 1,15 & 0,02 & 1,12 & $1,05 E+09$ \\
\hline 11 & 1,78 & 1,44 & 2,22 & $-1,16 E+07$ & 0,16 & 0,03 & 1,17 & $1,67 \mathrm{E}+08$ \\
\hline 12 & 0,72 & 3,56 & 2,22 & $-1,16 E+07$ & 1,20 & 0,02 & 1,32 & $1,04 \mathrm{E}+09$ \\
\hline 13 & 1,78 & 3,56 & 2,22 & $-1,16 E+07$ & 0,17 & 0,03 & 1,63 & $1,32 \mathrm{E}+08$ \\
\hline 14 & 0,72 & 1,44 & 12,78 & $-1,16 \mathrm{E}+07$ & 0,19 & 0,00 & 0,20 & $6,07 E+09$ \\
\hline 15 & 1,78 & 1,44 & 12,78 & $-1,16 \mathrm{E}+07$ & 0,02 & 0,00 & 0,17 & $1,14 \mathrm{E}+09$ \\
\hline 16 & 0,72 & 3,56 & 12,78 & $-1,16 \mathrm{E}+07$ & 0,19 & 0,00 & 0,23 & $6,02 E+09$ \\
\hline 17 & 1,78 & 3,56 & 12,78 & $-1,16 \mathrm{E}+07$ & 0,03 & 0,01 & 0,28 & $7,75 \mathrm{E}+08$ \\
\hline 18 & 0,72 & 1,44 & 2,22 & $-2,83 E+06$ & 1,10 & 0,02 & 1,13 & $1,05 E+09$ \\
\hline 19 & 1,78 & 1,44 & 2,22 & $-2,83 E+06$ & 0,16 & 0,03 & 1,23 & $1,58 \mathrm{E}+08$ \\
\hline 20 & 0,72 & 3,56 & 2,22 & $-2,83 E+06$ & 1,13 & 0,02 & 1,33 & $1,04 \mathrm{E}+09$ \\
\hline 21 & 1,78 & 3,56 & 2,22 & $-2,83 E+06$ & 0,16 & 0,03 & 1,58 & $1,38 \mathrm{E}+08$ \\
\hline 22 & 0,72 & 1,44 & 12,78 & $-2,83 E+06$ & 0,19 & 0,00 & 0,20 & $6,08 \mathrm{E}+09$ \\
\hline 23 & 1,78 & 1,44 & 12,78 & $-2,83 E+06$ & 0,03 & 0,01 & 0,22 & $8,93 E+08$ \\
\hline 24 & 0,72 & 3,56 & 12,78 & $-2,83 E+06$ & 0,19 & 0,00 & 0,23 & $6,02 E+09$ \\
\hline 25 & 1,78 & 3,56 & 12,78 & $-2,83 E+06$ & 0,03 & 0,01 & 0,27 & $7,94 \mathrm{E}+08$ \\
\hline
\end{tabular}

Table 2. Input parameters and finite element analysis results for orthogonal array. 